International Journal of Social Science and Economic Research

ISSN: 2455-8834

Volume:06, Issue:05 "May 2021"

\title{
EASY ACCESS OF INTERNET PORNOGRAPHY AND ITS IMPACT ON YOUTH: A REVIEW OF THE RESEARCH
}

\author{
Tanveer Ahamd Zoie ${ }^{1}$ and Showkat Rashid ${ }^{2}$ \\ ${ }^{1}$ Assistant Professor Sociology, Govt. Degree College Pulwama \\ ${ }^{2}$ Assistant Professor in Economics, Govt. Degree College Tral \\ DOI: 10.46609/IJSSER.2021.v06i05.001 URL: https://doi.org/10.46609/IJSSER.2021.v06i05.001
}

\begin{abstract}
In $21^{\text {st }}$ century, we clearly see how older patterns of group life and communications are being partially replaced by networking with the rise of information and communication technologies. The domestication of internet which began around the year 2000 has made things available around us. The penetration of internet has made availability of things just a click away from their accessibility. There is now easy availability of internet on laptop, mobile phone, video game, consoles and other electronic devices. The internet and internet enabled gadgets have transformed the word of sex, sexuality, pleasure, body. The tremendous growth of internet and its compatible devices has led to easy and more ubiquitous access to pornography. This has changed the way youth consume sexually explicit stuff. The purpose of this article is to review the recent literature on pornography and its impact on youth, their sexual attitude, behaviour, sexual orientation and sexual aggression. The impact of sexually explicit stuff on self-concept, body image ,concept of real pleasure, adolescent brain function and social development. The social and economic cost of using the pornographic stuff on adolescents who live in a cyber sexual world and pornified culture will be also taken into account.
\end{abstract}

Key Words: Internet, Youth, Pornography, Pornified culture, sexual stuff.

\section{INTRODUCTION}

The proliferation and mainstreaming of pornography over the last 2 decades, especially through the Internet, have influenced youth culture and adolescent development in unprecedented and diverse ways (Lofgren-Marten son 2010; Peter \& Valkenburg, 2007).Internet-enabled devices have indiscriminately allowed people of all ages to encounter, consume, create, and distribute sexually explicit content, and a growing body of data reveal these phenomena are increasingly common for adolescents worldwide (Flood, 2007; Haggstrom-Nordin, Sanberg, Hanson,\&Tyd'en, 2006; Lo \& Wei, 2005; Wolak, Mitchell, \& Finkelhor, 2007). Relative to other 


\section{International Journal of Social Science and Economic Research}

ISSN: $2455-8834$

Volume:06, Issue:05 "May 2021"

media, the Internet is considered a highly sexualized environment(Cooper, Boies, Maheu, \& Greenfield, 1999; Peter \& Valkenburg, 2006), and research has shown significant increases in the number of youth who are intentionally or accidentally encountering pornographic material online(Mitchell, Wolak, \& Finkelhor, 2007; Wolak et al., 2007).Given these circumstances, one may assume that adolescents' access to pornography via the Internet is unmatched by any other medium (Mitchell, Wolak, \& Finkelhor, 2007); the volume and range of sexually explicit content available on the Internet is remarkable. The evolving nature of techno-logically mediated pornographic content (e.g., real-time and interactional)provides novelty and variety at unprecedented speeds (Coopersmith, 2006).Additionally, the risk of cyber bullying, sexual victimization, or harassment from others is real and pervasive (Federal Bureau of Investigation, 2011).

\section{Access and impact of Pornography}

The Internet is present and prioritized in the lives of man .Given these circumstances, one may assume that adolescents' access to pornography via the Internet is unmatched by any other medium (Mitchell, Wolak, \& Finkelhor, 2007); the volume and range of sexually explicit content available on the Internet is remarkable. Furthermore, the Internet is present and prioritized in the lives of many youth (Lenhart, Ling, Campbell, \& Purcell, 2010; Lenhart, Purcell, Smith, \& Zickur, 2010; Mitchell et al., 2007). For example, in the United States, 93\%of all adolescents ages 12 to 17 use the Internet; $63 \%$ go online daily and36\% are online several times a day (Lenhart, Purcell et al., 2010). The World Internet Report surveyed 12 to 14 year olds from thirteen different countries and found that $100 \%$ of British youth, $98 \%$ of Israeli youth, $96 \%$ of Czech youth, and 95\% of Canadian youth reported using the Internet regularly(Lawsky, 2008). Given that the average American teen owns 3.5 mobile devices (Lenhart, Purcell et al., 2010), it can be assumed a great deal of their online activity is portable, and therefore, largely unmonitored (Roberts,Foehr, \& Rideout, 2005).

This increasingly ubiquitous access to the Internet can be positive; for example, people of all ages are turning to this medium for information on sexual education and sexual health (Barak \& Fisher, 2001), social connection(Cooper, Boies, Maheu, \& Greenfield, 1999), work, shopping, entertainment, news, and academics. On the other hand, unmonitored access for youth raises genuine concerns in light of the potential risks (Federal Bureau of Investigation, 2011); adolescents often lack the risk attenuation needed to discern and manage online dangers and content in safe and healthy ways(Delmonico \& Griffin, 2008). There is also a small, but growing, body of research that indicates adolescents are increasingly struggling with compulsive Internet use (CIU) and compulsive behaviors related to Internet pornography and cybersex (Delmonico \& Griffin, 2008; Lam, Peng, Mai, \& Jing, 2009 pornography websites allow users access that is simple and fast with no verification of age required (DeAngelis, 2007; Flood \& 
International Journal of Social Science and Economic Research

ISSN: 2455-8834

Volume:06, Issue:05 "May 2021"

Hamilton, 2003a; Shaffer, 2009; Wolak, Mitchell \& Finkelhor, 2007).This lack of restriction is evident in all forms of physical Internet access, including through computers, mobiles and iPods (Eberstadt \& Layden, 2010). Eberstadt and Layden (2010) reported that the homepages of 75\% of pornography websites studied included explicit and visual snippets of their content before requesting the age of viewers (with a mere $3 \%$ requiring some form of proof).

\section{Impact on Social relationships}

Viewing pornography while at a young age has been associated with a negative impact on the individual's intimate relationships. Whilst there is not extensive evidence in the research supporting this idea, it has been widely noted and reported in a variety of articles that pornography has the potential to undermine intimate relationships (Bryant, 2009). A high rate of exposure to pornographic material can limit how the young individual views members of the opposite gender, decreasing wholesome perceptions (De Angelis, 2007). Paul (2005) quoted sex therapist and psychologist, Aline Zoldbrod, in saying that "pornography doesn't show how a real couple negotiates conflict or creates intimacy" Basically; pornography can result in the young viewer having a skewed opinion of a 'normal' intimate relationship (De Angelis 2007). Married people who start watching porn are twice as likely to be divorced in the the following years as those who don't. And women who start watching porn are three times as likely to split, according to a working paper presented at the American Sociological Association on Aug. 22(Times, 2021)

\section{Effects of Desensitization and habituation}

Both these effects that have been connected to a high viewing rate of pornography. Excitatory habituation will result from a lengthy period of exposure to pornography, causing the individual to expand their viewing to material portraying more novel sexual activities in order to achieve the same goal as was initially sought when viewing (Zillmann, 2000). Desensitization can also occur, which can result in individuals acting out their fantasies (Cross on Tower, 2005). Thornburgh \& Lin (2002) reported that in a study of 19 to 20 year olds who viewed an hour of an R-rated equivalence film that contained sexual violence, desensitization occurred immediately with arousal decreasing during viewing after this hour, and a lessened empathy toward the victims of sexual violence shown in the films. One of the most popular new forms of sexual expression and sexual behaviour is 'sexting'. Basically, 'sexting' "refers to sending and receiving sexually suggestive images, videos, or texts on cell phones [mobiles] (Weisskirch \& Delve, 2011). This can occur either in an 'aggravated' manner, whereby criminal action is involved (for example, a sexual predator requesting images or an 'experimental' manner, where by the individual acts out of romantic interests or a need for attention (Wolak \& Finkelhor, 2011). 
International Journal of Social Science and Economic Research

ISSN: 2455-8834

Volume:06, Issue:05 "May 2021"

\section{Gender relations and Pornography}

When discussing the impact of pornography, it is crucial to take a gender-based lens where we start from the empirically verified observation that males and females are affected differently by the hyper sexualized pop culture and pornography. Research from the American Psychological Association informs us that girls who internalize the messages of the hyper sexualized pop culture tend to have more depress ion, anxiety, lower self-esteem, eating disorders, and risky sexual behavior. Moreover, girls are more at risk for rape, battery, and being trafficked in a society where pornography is normalized. While girls are not the major consumers of pornography, they suffer the consequences because they engage in sexual relationships with boys and men who have had their sexual templates shaped by mainstream online violent pornography. A gender-based lens also demands that we understand boys as victims of this predatory industry (Gail Dines,2014 ).Boys who are exposed to mainstream online violent pornography are increasingly being traumatized by the cruel images that assault them when they put porn into a Google search. Research shows that an adolescent brain is primed for novelty and risk taking, and the pornography industry has hijacked this developmental stage by targeting boys as potential consumers(Eric W. Owens, et al., 2012).Studies reveal that the more young people are exposed to porn, the harder it is for them to form intimate relationships as they move through adolescence into adulthood (Jochen Peter and Patti M. Valkenburg,2008).In terms of social predictors of pornography use, researchers dealt with family-related and peer related variables as well as with victimization. Less commitment to the family (Mesch,2009; Mesch \& Maman,2009), poor family functioning in general (Shek \& Ma,2014), and specifically less mutuality in family functioning (Shek \& Ma,2012). Weaker pro-social attitudes also correlated with more frequent pornography use (Mesch,2009;Shek \& Ma,2012a). Restrictive parental mediation (Sevcikováet al.,2014) and installed blocking software (Wolak et al.,2007)were associated with less pornography use on the Internet. In contrast, the variables of parental control and parents talking about Internet pornography with their children were found to be unrelated to adolescents' use of Internet pornography (Peter \&Valkenburg,2006a; Wolak et al.,2007). The study on the use of pornography on mobile phones also showed that popularity with same-sex peers, popularity with opposite-sex peers, desire for popularity, and peer pressure were linked with more frequent pornography use (Vanden Abeele et al.,2014). Attachment to peers, however, has been found to be unrelated to adolescents' use of Internet pornography (Mesch \& Maman,2009). Finally, regarding victimization, Wolak et al. (2007) found that adolescents were more likely to use internet pornography when they were harassed online and victimized in their offline lives. The Typical Adolescent Pornography user is a Male, pubertally more advanced, sensation-seeker, with weak or troubled family relations .Research has studied a plethora of predictors of adolescents'use of pornography. However, cumulative evidence of what predicts adolescents'use of pornography is still somewhat limited. Although there are no generally 


\section{International Journal of Social Science and Economic Research}

ISSN: $2455-8834$

Volume:06, Issue:05 "May 2021"

accepted standards about the number of replications needed to establish cumulative evidence, there is agreement that research findings should be reproduced at least once and preferably more times(e.g., Casadevall \& Fang,2010). In this review, we define cumulate evidence as the same result obtained by at least three different research teams in at least three different samples for identical (or conceptually close) predictors in the absence of a considerable number of opposing results. Against this background we can tentatively conclude that the most likely users of pornography are male, pubertally more advanced, sensation-seeking adolescents with weak or troubled family relations. However, it is important to note that the predictors of pornography use may change as access to pornography or the cultural context of pornography change. For example, if the Internet is accessible only for the privileged or skilled, those who access pornography on the Internet may differ strongly from those who access it if the Internet is accessible to everyone. Similarly, if pornography is normalized in a culture, its use may be predicted by a very different set of variables than when it is considered deviant. Sexual Attitudes terms of sexual attitudes, research has centered on two types of attitudes: permissive sexual attitudes and gender-stereotypical sexual beliefs. We use the term permissive sexual attitudes as an umbrella term for positive attitudes toward sex with casual partners, typically in an uncommitted setting or outside a romantic relationship. In the literature, permissive sexual attitudes have been assessed with measures such as sexually non exclusive attitudes (Loet al.,1999), instrumental attitudes toward sex (Peter \&Valkenburg,2010b), attitudes toward uncommitted sexual exploration (Peter \& Valkenburg,2008b), or attitudes toward sexually permissive behavior (Lo \& Wei,2005)

\section{Social Development and Pornography}

social development is concerned a number of studies address the impact of sexually explicit material on adolescents' social development, attachment, and interpersonal relationships. For example, Mesch (2009) used a 2004 sample of Israelis aged 13-18 in an effort to describe social characteristics of pornography consumers. Using quantitative methodology, the study found that adolescents with higher degrees of social interaction and bonding were not as likely to consume sexually explicit material as were their less social peers (Mesch, 2009). Additionally, Mesch found that greater quantities of pornography consumption were significantly correlated with lower degrees of social integration, specifically related to religion, school, society, and family. The study also found a statistically significant relationship between pornography consumption and aggressiveness in school, with higher degrees of consumption related to higher levels of aggressiveness (Mesch, 2009). In a similar study Alexy etal. (2009) studied the pornography consumption patterns of juvenile sexual offenders as they related to various forms of aggressive behavior. Those who were consumers of pornography were more likely to display forms of aggressive behaviors such as theft, truancy, manipulating others, arson, and forced sexual . 
International Journal of Social Science and Economic Research

ISSN: 2455-8834

Volume:06, Issue:05 "May 2021"

\section{Brain function and pornography}

Studies examining the impact of pornography consumption in the cortical substrates in the brains of healthy control adolescent subjects are non-existent at this time. However, neuroscience research has advanced several findings in the literature that have potential implications for work with adolescents who are regularly exposed to sexually explicit material, and who may be at risk for abnormal developmental trajectories. Some perspectives on adolescent neurocortical vulnerability to pornography consumption are drawn from the work of researchers in medicine and pathological gambling, and from neuroscientists studying developmental psychology (Casey et al.,2008; Chambers et al., 2003); these may be limited in their application to adolescent consumption of pornography. Nevertheless, these perspectives can provide a basis for hypothesis generation and avenues for future research in the area of adolescent use of pornography. A constellation of significant change occurs during adolescence and many of these changes are influenced by rewards (Somerville et al., 2010).For adolescents, reward-seeking behaviors commonly occur in the pursuit of money, novelty, excitement, and social connection, including peer-group acceptance, sexual activity, and substance use (Steinberg, 2008). Developmentally, risk-taking and reward-seeking decision-making behaviors promote growth and learning for a majority of adolescents. However, evidence from the field of neuroscience suggests that these tendencies may also be associated with a vulnerability to excess in high risk behaviors (Casey \& Jones,2010; Chambers et al., 2003; Doremus-Fitzwater, Varlinskaya, \& Spear, 2010).

Differences in neurobiology between adolescent and adult brain systems have been well documented (e.g., Asato, Terwilliger, Woo, \& Luna,2010; Gogtay, et al., 2004). Although cortical dimensions of brain size in 6-year-old children have reached approximately $90 \%$ of those found in adults(Casey, Galvan, \& Hare, 2005), changes continue to emerge for gray and white matter substrates during adolescence and continue well into young adulthood (Giedd, 2004; Gogtay et al., 2004; Sowell et al., 2003). For example, significant neuroanatomical differences emerge between adults and adolescents in the frontal cortices and in the striatum (Sowell et al., 1999), the regions generally presumed to be associated with executive control and affect regulation (Alvarez \& Emory, 2006; Costafreda, Brammer, David, \&Fu, 2008; YurgelunTodd, 2007). These differences, often measured through functional magnetic resonance imaging (fMRI), have also been the impetus for explanations about how adolescents may process reward stimuli inthe brain as compared to adults (e.g., Casey et al., 2008; Ernst, Romeo, \&Andersen, 2009).

\section{Bibliography}


International Journal of Social Science and Economic Research

ISSN: 2455-8834

Volume:06, Issue:05 "May 2021"

1.Gail Dines, Pornland. Bacon press Boston,massachustess.

2.Eric W. Owens, et al., "The Impact of Internet Pornography on Adolescents: A Review of the Re-search,” Sexual Addiction \& Compulsivity19.1-2 (2012): 99-122.

3.Jochen Peter and Patti M. Valkenburg, “Adolescents' Exposure to Sexually Explicit Internet Mate-rial, Sexual Uncertainty, and Attitudes toward Uncommitted Sexual Exploration, Is There a Link?" Communications Research35, no. 5 (2008): 579-601.

4.Eberstadt,M. \& Layden, M. A. (2010). The Social Costs of Pornography: A Statement of Findings and Recommendations. USA: The Witherspoon Institute.

5.Alexy, E. M., Burgess, A. W., \& Prentky, R. A. (2009). Pornography use as a riskmarker for an aggressive pattern of behavior among sexually reactive childrenand adolescents.Journal of the American Psychiatric Nurses Association,42,442-453

6.Alvarez, J. A., \& Emory, E. (2006). Executive function and the frontal lobes: A meta-analytic review.

7.Revisiting the picture-superiority effect in symbolic comparisons: Do pictures provide privileged ac-cess?Journal of Experimental Psychology: Learning, Memory, and Cognition,28(5), 843-857.

8.Arieh, Y., \& Algom, D. (2002). Processing picture-word stimuli: The contingent nature of picture and of word superiority.Journal of Experimental Psychology:Learning, Memory, and Cognition, 28, 221-231

9.Asato, M. R., Terwilliger, R., Woo, J., \& Luna, B. (2010). White matter development in adolescence: A DTI study.Cerebral Cortex,20, 2122-2131.

10.Barak, A., \& Fisher, W. A. (2001). Toward an Internet-driven, theoretically-based innovative approach to sex education.Journal of Sex Research, 38, 324-332.Braun-Courville, D. K., \& Rojas, M. (2009).

11.Brown, J. D., Keller, S., \& Stern, S. (2009). Sex, sexuality, sexting, and sexed: Adolescents and the media.The Prevention Researcher,16(4), 12-16.

12.Carroll, J. S., Padilla-Walker, L. M., Nelson, L. J., Olson, C. D., Barry, C. M. \&Madsen, S. D. (2008). Generation XXX: Pornography acceptance and use among emerging adults.Journal of Adolescent Research,23, 6-30. 
International Journal of Social Science and Economic Research

ISSN: 2455-8834

Volume:06, Issue:05 "May 2021"

13.Casey, B. J., \& Jones, R. M. (2010). Neurobiology of the adolescent brain and behavior: Implications for substance use disorders.Journal of the American Academyof Child \& Adolescent Psychiatry,49(12), 1189-1201

14.Casey, B. J., Jones, R. M., \& Somerville, L. H. (2011). Braking and accelerating of the adolescent brain.

15.Cooper, A., Boies, S., Maheu, M., \& Greenfield, D. (1999). Sexuality and the Inter-net: The next sexual revolution.

16.F. Muscarella \& L. Szuchman (Eds.),The psychological science of sexuality: A research based approach(pp. 519-545).New York:

17.Wiley.Coopersmith, J. (2006). Does your mother know what you reallydo? The changing gimage and nature of computer based pornography.

18. Dines, Gail. Pornland: How Porn Has Hijacked our Sexuality. Boston: Beacon Press, 2010.

19. https://www.youtube.com/watch?v=_YpHNImNsx8\&t=12s.Flood, Michael.

20. "Exposure to Pornography among Youth in Australia." Journal of Sociology43 (2007).

21."Pornography Viewing among Fraternity Men: Effects on Bystander Intervention, Rape Myth Acceptance and Behavioral Intent to Commit Sexual Assault." Sexual Addiction \& Compulsivity18, no. 4 (2011):212-231. doi: DOI: 10.1080/10720162.2011.625552.

22.Hilton, Donald. "Pornography Addiction -A Supra normal Stimulus Considered in the Context of Neuroplasticity." Socio affected Neuroscience 3 (2013).

23.Owens, Eric W., et al. "The Impact of Internet Pornography on Adolescents: A Review of the Research.” Sexual Addiction \& Compulsivity19.1-2 (2012): 99-122.

24.Peter, Jochen and Patti M. Valkenburg. "Adolescents and Pornography: A Review of 20 Years of Research." The Journal of Sex Research(2016): 1-23. doi: 10.1080/00224499.2016.1143441.

25. "Adolescents' Exposure to Sexually Explicit Internet Material, Sexual Uncertainty, and Attitudes toward Uncommitted Sexual Exploration, Is There a Link?" Communications Research35, no.5 (2008): 579-601. 
26. Smith, Lucy W., Bette Liu, Juliet Richters, George Patton, Handan Wand, Donna Cross, Jane S. Hocking, et al. "Is Sexual Content in New Media Linked to Sexual Risk Behaviour in Young People? A Systematic Review and Meta-Analysis.” Sex Health(2016). doi: 10.1071/SH16037

27.Sun, Chyng, Ana J. Bridges, Jennifer A. Johnson, and Matthew B. Ezzell. "Pornography and the Male Sexual Script: An Analysis of Consumption and Sexual Relations." Archives of Sexual Behavior(2014): 1-12. doi: 10.1007/s10508-014-0391-2

28.Bridges, Ana J. "Pornography's Effects on InterpersonalRelationships." In The Social Costs of Pornography, edited by James R. Stoner and Donna M. Hughes, 89-110. Princeton: Witherspoon Institute, 2010.

29.Bronfenbrenner, Urie. "Ecological Models of Human Development." In International Encyclopedia of Education3, 2ndEdition. Oxford: Elsevier, 1994. 